\title{
Intestinal Folate Absorption
}

\author{
II. CONVERSION AND RETENTION \\ OF PTEROYLMONOGLUTAMATE BY JEJUNUM
}

\author{
Edward J. Olinger, Joseph R. Bertino, and Henry J. Binder \\ From the Departments of Internal Medicine and Pharmacology, Yale \\ University, New Haven, Connecticut 06510
}

A в S T RACT These studies were designed to determine whether pteroylmonoglutamic acid (PGA) at physiologic concentrations is transported across the small intestine unaltered or is reduced and methylated to the circulating folate form (5-methyltetrahydrofolate [5- $\left.\mathrm{MeFH}_{4}\right]$ ) during absorption. $\left[{ }^{3} \mathrm{H}\right] \mathrm{PGA}$ was incubated in vitro on the mucosal side of rat jejunum. Of the folate transferred to the serosal side, the percent identified as $5-\mathrm{MeFH}_{4}$ by DEAE-Sephadex chromatography was inversely related to the initial mucosa PGA concentration: at 7,20, and $2.000 \mathrm{nM}, 44 \%, 34 \%$, and $2 \%$, respectively, was converted to $5-\mathrm{MeFH}_{4}$. In contrast, less than $4 \%$ of the folate transferred across ileal mucosa was $5-\mathrm{MeFH}_{4}$ when the initial mucosa concentration was $20 \mathrm{nM}$. Specific activity of dihydrofolate (DHF) reductase, the enzyme responsible for converting PGA to tetrahydrofolic acid, was measured in villus homogenates and was significantly greater in the jejunum than in the ileum. $1,000 \mathrm{nM}$ methotrexate (MTX), a DHF reductase inhibitor, markedly inhibited PGA conversion to $5-\mathrm{MeFH}_{4}$ by the jejunum.

Studies of transmural flux, initial rate of mucosal entry (influx) and mucosal accumulation (uptake) of folate were also performed. Although MTX did not alter the influx of PGA, MTX decreased jejunal mucosal uptake but increased transmural movement. Trans-

This work was presented in part at a joint meeting of the American Society of Clinical Investigation and American Federation of Clinical Research, in Atlantic City, 30 April 1972 and appeared in abstract form (1972. Clin. Res. 20: 462).

Dr. Olinger was a recipient of the Norman Jolliffe Student Fellowship from the American Society of Clinical Nutrition. Dr. Bertino is a recipient of a Career Development Award of the National Cancer Institute.

Address reprint requests to Dr. Binder.

Received for publication 15 September 1972 and in revised form 6 April 1973. mural folate movement across ileal mucosa was greater than across jejunal mucosa although mucosal uptake was greater in the jejunum than in the ileum.

These results could explain previous studies which have failed to identify conversion of $\mathrm{PGA}$ to $5-\mathrm{MeFH}_{4}$ when intestinal preparations have been exposed to higher and less physiologic concentrations of PGA. Further, these studies suggest that $5-\mathrm{MeFH}_{4}$ may be retained by the jejunal mucosa.

\section{INTRODUCTION}

Most studies of intestinal folate absorption in man and animals (1-8) have centered around pteroylmonoglutamic acid $(\mathrm{PGA})^{1}$ which is stable and readily available. Less than $10 \%$ of dietary folate, however, is PGA (9). In the diet folate is found predominantly as polyglutamates of several reduced folate compounds, primarily 5-methyltetrahydrofolic acid $\left(5-\mathrm{MeFH}_{4}\right)(9-11)$.

Despite much study, there is still disagreement over the mechanism of PGA absorption (12). Whether PGA is absorbed preferentially in the jejunum or in the ileum, whether it is absorbed by active transport or by diffusion, whether it is transferred across the intestinal mucosa intact or converted to other folate forms during its transfer, and whether it is utilized by the intestine with or without conversion to reduced and methylated compounds remain unknown. Recently developed chromatographic methods which permit identification of folate compounds have been utilized in this study to determine whether at physiologic concentrations PGA is

\footnotetext{
${ }^{1}$ Abbreviations used in this paper: DHF, dihydrofolate; $\mathrm{FH}_{4}$ tetrahydrofolic acid; 5- $\mathrm{MeFH}_{4}$, 5-methyltetrahydrofolic acid; MTX, methotrexate; pABG, $p$-aminobenzoylglutamate; PGA, pteroylmonoglutamate or folic acid; TK, thymidine kinase. Folate is used to refer to all folate compounds, both reduced and nonreduced.
} 
converted to other folate forms during its transfer across the rat intestinal mucosa.

\section{METHODS}

\section{Materials}

$\left[{ }^{3} \mathrm{H}\right] \mathrm{PGA}$ was purchased from Amersham Searle Corp. (Arlington Heights, Ill.) and $\left[2{ }^{11} \mathrm{C}\right]$ thymidine and $\left[{ }^{3} \mathrm{H}\right]-$ inulin from New England Nuclear Corp. (Boston, Mass.). Unlabeled PGA and methotrexate (MTX) were obtained through the courtesy of Lederle Laboratories (Pearl River, N. Y.). All other compounds used were obtained from commercial sources.

\section{Identification of folate compounds by chromatography (13)}

Samples were desalted by chromatography through a Sephadex G-15 Column equilibrated with $0.1 \mathrm{M}$ mercaptoethanol and eluted by the same solvent. Fractions which contained radioactivity or folate markers were pooled and applied to a $0.9 \times 27 \mathrm{~cm}$ column of A-25 DEAE Sephadex equilibrated with $0.1 \mathrm{M}$ phosphate buffer, $\mathrm{pH} 6.0$, containing $20 \mathrm{mM}$ mercaptoethanol. Materials were eluted by phosphate buffer, $\mathrm{pH} 6.0$, the concentration of which was increased linearly from 0.1 to $2.0 \mathrm{M}$ also containing $20 \mathrm{mM}$ mercaptoethanol. The final concentration of $2.0 \mathrm{M}$ phosphate buffer was obtained after passage of $500 \mathrm{ml}$ of eluting buffer. Nonradioactive markers of $5-\mathrm{MeFH}_{4}, \mathrm{PGA}, 5-10$ methylene $\mathrm{FH}_{4}$, and paraminobenzoic acid (pABG) were added with the sample when applicable. Fractions of $2.5 \mathrm{ml}$ were collected and monitored by radioactivity and by ultraviolet absorbance spectra.

This system separates monoglutamate folate forms reasonably well; there was some overlap between the 5-10 methylene $\mathrm{FH}_{4}$ peaks and $5-\mathrm{MeFH}_{4}$, but the peak tubes of these compounds were separable (13). Good separation between 5-MeFH, and PGA and 5-10 methenyl $\mathrm{FH}_{4}$ was achieved with only slight overlap between peaks. Quantitation of various folate forms was accomplished by manual integration, correcting for overlap where necessary.

The tritiated PGA was purified by column chromatography first on A-25 DEAE-Sephadex, then on Sephadex G-25 and, when utilized, was greater than $99 \%$ radiochemically pure.

\section{Transport studies}

Nonfasting male Sprague-Dawley rats weighing 300-350 g were used in all experiments. Intestinal folate transport was studied by several in vitro techniques: mucosal influx (14) and uptake (15) and unidirectional transmural movement (16).

Transmural folate transfer. Mucosal to serosal transfer of $\left[{ }^{3} \mathrm{H}\right] \mathrm{PGA}$ was determined using the methods and apparatus described by Schultz and Zalusky (16) as previously modified (17). Briefly, flat sheets of rat jejunum or ileum were mounted between Lucite chambers. Unlabeled PGA at either 7,20, or 2,000 $\mathrm{nM}$ was placed on both the mucosal and serosal side of the tissue with approximately $3.0 \mu \mathrm{Ci}$ of $\left[{ }^{3} \mathrm{H}\right]$ PGA added to the mucosal solution. All experiments were performed protected from light. Both sides of the tissue were bathed in identical solutions maintained at $37^{\circ} \mathrm{C}$ and bubbled continuously with $\mathrm{O}_{2}-\mathrm{CO}_{2}(95: 5$, vol/vol). In all experiments, the composition of the Ringer bathing solution was: $\mathrm{Na} 140 \mathrm{mM} ; \mathrm{Cl}, 119.8 \mathrm{mM} ; \mathrm{HCO}_{3}, 25 \mathrm{mM}$;
$\mathrm{H}_{2} \mathrm{PO}_{4}, 0.4 \mathrm{mM} ; \mathrm{HPO}_{4}, 2.4 \mathrm{mM} ; \mathrm{Mg}, 1.2 \mathrm{mM} ; \mathrm{Ca}, 1.2 \mathrm{mM}$; $\mathrm{K}, 5.2 \mathrm{mM}$, and ascorbic acid, $10 \mathrm{mM}$. The $\mathrm{pH}$ was maintained at 7.4. After a $20 \mathrm{~min}$ incubation period, the rate of appearance of the radiolabeled material in the serosal solution was determined for four $20 \mathrm{~min}$ periods. Samples (1 $\mathrm{ml}$ ) were added to Bray's solution and were counted in a liquid scintillation spectrometer. In these studies results were expressed as picomoles of folate transferred to the serosal solution per square centimeter of tissue per hour.

At the conclusion of the 100 min experimental period, appropriate mucosal and serosal bathing solutions from two to three experiments were pooled and stored overnight in $3 \mathrm{M}$ mercaptoethanol at $4^{\circ} \mathrm{C}$. Identification of the folate transferred to the serosal side was then determined by column chromatography (vide supra). Compounds identified were quantitated in terms of picomoles transferred to the serosal solution per square centimeter per hour by combining the relative proportion of each compound transferred as determined by the chromatographic analysis with the total mucosal to serosal folate transfer. The relative proportion of each compound was calculated by expressing the amount of the folate isolated over the total folate recovered on chromatography as a percentage.

Mucosal influx and uptake of folate were determined by modification of the tissue accumulation method (15). Short (1-2 cm, 100-150 mg), everted segments of jejunum and ileum filled with a Ringer buffer were placed in flasks containing $20 \mathrm{nM}$ PGA with and without 1,000 nM MTX. The flasks were continuously oxygenated during incubation periods which varied from 0.6 to $60 \mathrm{~min}$. At the end of the incubation, the tissue was removed, washed in $0.3 \mathrm{M}$ mannitol, drained, blotted, weighed, and placed in boiling water for $5 \mathrm{~min}$. Aliquots of the boiling water extract and the mucosal incubation media were obtained for liquid scintillation counting. The tissue was dried at $110^{\circ} \mathrm{C}$ overnight and weighed. Inulin space was determined in separate experiments at all incubation periods and experimental conditions and utilized to correct for the extracellular space. The results were expressed as picomoles of folate accumulated per hour per milligram dry tissue weight.

Tissue uptake represents the accumulation of folate under steady-state conditions. After preliminary studies demonstrated that tissue accumulation had reached equilibrium by $30 \mathrm{~min}$, a $40 \mathrm{~min}$ incubation period was employed for determination of mucosal uptake. Mucosal influx measures the initial rate of entry of a substance from the external media to the mucosal cell and must be determined during a period of time when mucosal accumulation is linear with respect to time. Therefore, shorter incubation periods are required to determine mucosal influx than are required for mucosal uptake determinations. In additional preliminary experiments, mucosal accumulation was observed to be linear during incubation periods up to two minutes. Therefore, 1 min incubation periods were employed for determination of mucosal influx.

\section{Intestinal enzyme analyses}

In another series of experiments, homogenates of both the total mucosa and relatively pure villi were obtained, and dihydrofolate (DHF) reductase, thymidine kinase (TK), and sucrase activities were assayed. In these studies, the small intestine was removed, placed in cold $5 \times 10^{-5} \mathrm{M}$ Tris buffer with $10^{-4} \mathrm{M}$ thymidine, $\mathrm{pH} 7.5$ (tris-thymidine buffer). The small intestine was divided into three equal parts of approximately $30 \mathrm{~cm}$ in length after flushing with the tris-thymidine buffer. The middle segment was dis- 

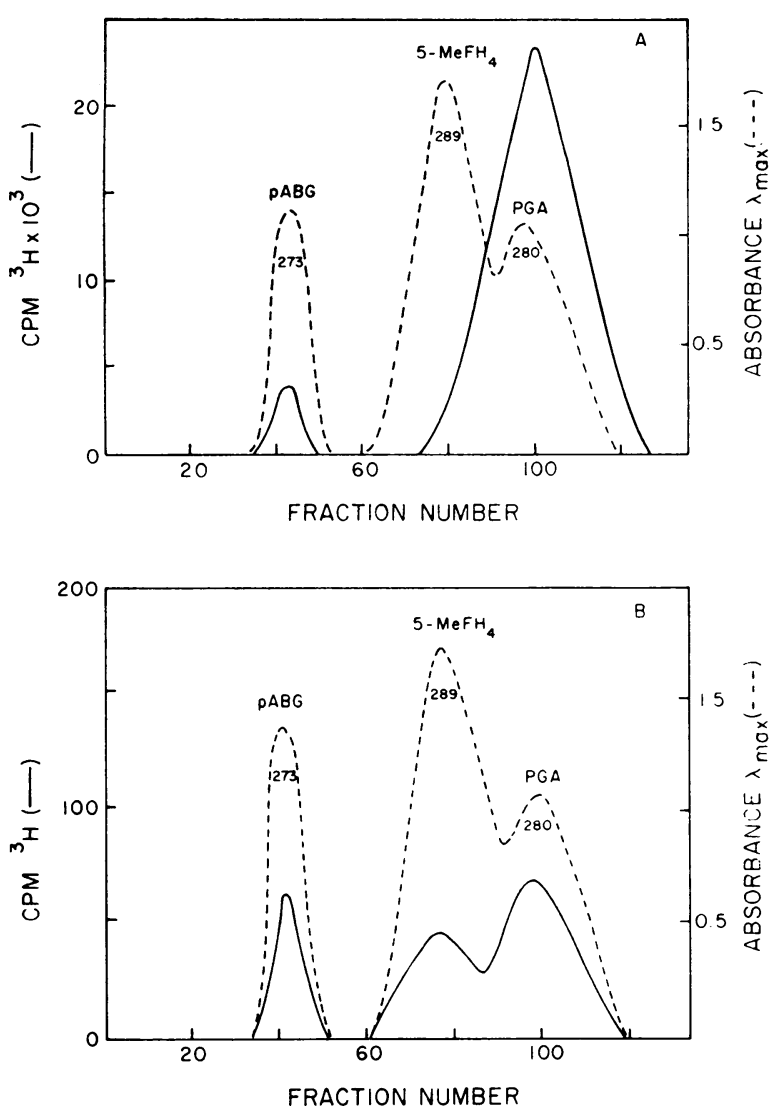

Figure 1 DEAE-Sephadex chromatography (13) of pooled mucosal $(A)$ and serosal $(B)$ fluid from rat jejunum after $100 \mathrm{~min}$ incubation with $7 \mathrm{nM}$ PGA. (A) Mucosal sample reveals predominant $\mathrm{PGA}$ peak, no $5-\mathrm{MeFH}_{4}$, and small amount of pABG which is a folate breakdown product. $(B)$ In contrast to mucosal sample shown in $4.44 \%$ of the folate present in the serosal media after transmural transfer is $5-\mathrm{MeFH}_{4}$.

carded and the proximal and distal segments were used as jejunal and ileal segments, respectively. Each segment was lightly scraped along the mucosa as described by Dietschy and Siperstein (18) to separate the intestinal villi from the remaining mucosal and muscular layers. This preparation is hereafter referred to as the villus preparation. Additional tissue underwent a more forceful scraping to separate total mucosa from the underlying smooth muscle layer and is referred to as the total mucosal preparation. Histologic evaluation of these intestinal layers were determined on formalin-fixed, hematoxylin- and eosin-stained sections of each preparation. The jejunal and ileal villi and the total mucosal fraction were individually homogenized for 1-2 min. The homogenates were centrifuged for $15 \mathrm{~min}$ at $27,000 \mathrm{~g}$ and the supernatant fluid from each homogenate was divided into three equal aliquots. One aliquot was used for immediate determination of $\mathrm{TK}$ activity, and the other two were stored at $-70^{\circ}$ until used for determination of DHF reductase activity, sucrase activity, and protein content.

Thymidine kinase activity was determined using the assay of Chello and Jaffe (19) and the chromatographic separation of Furlong (20). The thymidine kinase activity is expressed as picomoles of thymidine-5 monophosphate formed per milligram protein per $30 \mathrm{~min}$.

Dihydrofolate reductase activity was determined at $\mathrm{pH} 7.5$ at $37^{\circ} \mathrm{C}$ using the method of Bertino, Perkins, and Johns (21). Activity is expressed as nanomoles of DHF reduced per hour per milligram protein.

Sucrase activity was determined according to the method of Dahlquist (22) and activity is expressed as micrograms of glucose liberated per hour per milligram protein. Protein concentrations were determined by the biuret method with bovin serum albumin as the standard.

\section{Statistics}

Results are expressed as mean \pm SEM and the statistical significance determined by the student $t$ test (23).

\section{RESULTS}

Transmural PGA transfer. Measurement of transmural folate movement was determined at 7,20 , and 2,000 nM PGA mucosal concentration. The total folate transferred increased with increasing initial mucosal concentration (Table I). Although separation of folate compounds on DEAE-Sephadex chromatograph revealed only the initial PGA in the mucosal solution following incubation (Fig. $1 \mathrm{~A}$ ), significant amounts of $5-\mathrm{MeFH}_{4}$ were found in the serosal solution following transmural mucosal transport. Results of chromatography of a serosal solution in which $7 \mathrm{nM}$ PGA was present initially in the mucosal solution is shown in Fig. $1 B$. Approximately $44 \%$ of folate transferred under these conditions were chromatographically identified as 5- $\mathrm{MeFH}_{4}$. At an initial mucosal PGA concentration of $20 \mathrm{nM}$ the percent of the serosal folate that appeared as $5-\mathrm{MeFH}_{4}$ decreased to $34 \%$ and at $2,000 \mathrm{nM}$ this further decreased to $2 \%$. Although the percent appearing as $5-\mathrm{MeFH}_{4}$ decreased with increasing initial PGA mucosal concentration, the total amount of $5-\mathrm{MeFH}_{4}$ transported to the serosal solution increased. For example, at $7 \mathrm{nM}$ the $5-\mathrm{MeFH}_{4}$ flux was $0.072 \mathrm{pmol} / \mathrm{h}$ per $\mathrm{cm}^{2}$; while at 2,000 nM, 5-MeFH، flux was $0.776 \mathrm{pmol} / \mathrm{h}$ per $\mathrm{cm}^{2}$ ( Table I).

The conversion of $\mathrm{PGA}$ to $5-\mathrm{MeFH}_{4}$ involves initial reduction of PGA to $\mathrm{FH}_{4}$ (24). Methotrexate (MTX), a DHF reductase inhibitor, prevents the conversion of PGA to $\mathrm{FH}_{4}$. Therefore, another series of experiments were performed in which $20 \mathrm{nM}$ PGA was present on the mucosal side of the jejunum with $1,000 \mathrm{nM}$ MTX (Table II). Under these conditions, the percent of folate in the serosal solution appearing as $5-\mathrm{MeFH}_{4}$ was markedly reduced. In the presence of MTX, $6 \%$ of the folate appearing in the serosal solution was $5-\mathrm{MeFH}_{4}$; however, the total transmural folate movement was significantly increased. Therefore, the amount of PGA transferred across the jejunum in the presence of MTX increased.

Studies to compare PGA transfer at a $20 \mathrm{nM}$ mucosal concentration in the ileum with that in the jejunum 
TABLE I

Transmural Movement of PGA across Rat Jejunum: Effect of Concentration

\begin{tabular}{cccc}
\hline Concentration & Folate flux* & $\% 5-\mathrm{MeFH}_{4} \neq$ & $\begin{array}{c}5-\mathrm{MeFH}_{4} \\
\text { flux }\end{array}$ \\
\hline$n M$ & & & \\
7 & $\begin{array}{c}0.157 \pm 0.009 \\
(9)\end{array}$ & 44 & 0.072 \\
20 & $\begin{array}{c}0.279 \pm 0.016 \\
(13)\end{array}$ & 34 & 0.095 \\
2,000 & $\begin{array}{c}38.78 \pm 3.05 \\
(6)\end{array}$ & 2 & 0.776 \\
& & &
\end{tabular}

* Transmural fluxes of PGA determined as described in text and expressed as picomoles per hour per $\mathrm{cm}^{2}$. Number of tissues used for flux determination is number in parenthesis. Mean \pm SEM.

$\ddagger$ Percent of total folate appearing on serosal side of tissue identified by chromatographic analysis (14) as $5-\mathrm{MeFH}_{4}$.

were also performed. Table II demonstrates that the percent of folate appearing as $5-\mathrm{MeFH}_{4}$ on the serosal side following incubation with ileal mucosa is significantly less than with jejunal mucosa. Less than $4 \%$ of the folate transferred across ileal mucosa was $5-\mathrm{MeFH}_{4}$. However, transmural flux of folate across ileal mucosa is significantly greater than across jejunal mucosa.

Mucosal influx. Two groups of tissue accumulation studies were performed. One group was performed in which the incubation period lasted approximately $1 \mathrm{~min}$ in order to determine the initial rate of mucosal entry (influx). Results shown in Table III demonstrate that mucosal influx in the jejunum at $20 \mathrm{nM}$ was similar with and without MTX. Jejunal mucosal influx is greater than ileal influx.

Mucosal uptake. Additional accumulation studies were performed in which 40 min incubation periods were used

TABLE II

Transmural Movement of $20 n M$ PGA across Rat Intestine: Jejunum vs. Ileum; Effect of $10^{-6} \mathrm{M}$ Methotrexate $(M T X)^{*}$

\begin{tabular}{|c|c|c|c|c|}
\hline Tissue & MTX & Folate flux & $\%$ 5-MeFH4 & $\begin{array}{l}\text { 5-MeFH4 } \\
\text { fllux }\end{array}$ \\
\hline Jejunum & Absent & $\begin{array}{c}0.279 \pm 0.016 \\
(13)\end{array}$ & 34 & 0.095 \\
\hline Jejunum & Present & $\begin{array}{c}0.392 \pm 0.025 \ddagger \\
\text { (9) }\end{array}$ & 6 & 0.024 \\
\hline Ileum & Absent & $\begin{array}{c}0.392 \pm 0.045 \S \\
(6)\end{array}$ & $<4$ & $<0.016$ \\
\hline
\end{tabular}

* See footnotes to Table I.

$\ddagger P<0.005$ compared with jejunum without $10^{-6}$ M MTX. $\$ P<0.05$ compared with jejunum.
TABLE III

Mucosal Influx and Uptake of 20 nM PGA: Jejunum is. Ileum; Effect of Methotrexate $(M T X)^{*}$

\begin{tabular}{cccc}
\hline Tissue & $10^{-6}$ M MTX & Mucosal influx & Mucosal uptake \\
\hline Jejunum & Absent & $312.2 \pm 46.8$ & $70.3 \pm 5.4$ \\
& & $(16)$ & $(15)$ \\
Jejunum & Present & $329.6 \pm 43.5$ & $49.3 \pm 2.9 \ddagger$ \\
& & $(10)$ & $(12)$ \\
Ileum & Absent & $100.4 \pm 32.6 \S$ & $3.5 \pm 0.5 \|$ \\
& & $(11)$ & $(11)$ \\
\hline
\end{tabular}

* Mucosal influx determined in 1 min incubations; uptake in 40-min incubations. Results (mean $\pm \mathrm{SEM}$ ) expressed as picomoles per hour per milligram dry tissue weight. Number in parenthesis is number of experiments.

$\ddagger P<0.01$ compared with jejunum without $10^{-6}$ M MTX.

$\S P<0.01$ compared with jejunum.

$\| P<0.001$ compared with jejunum.

to determine net mucosal uptake. In these studies (Table III), mucosal uptake in the jejunum is significantly inhibited by the presence of MTX. Jejunal uptake was $70.3 \pm 5.4 \mathrm{pmol} / \mathrm{h}$ per $\mathrm{mg}$ dry tissue weight and in the presence of MTX jejunal uptake was $49.3 \pm 2.9 \mathrm{pmol} / \mathrm{h}$ per mg dry tissue weight. Jejunal uptake is also greater than ileal uptake.

DHF reductase activity. DHF reductase specific activity was determined in both the total mucosal and villus preparations. Table IV demonstrates that DHF reductase specific activity was slightly but not significantly greater in the jejunal than in the ileal total mucosal preparation. The total mucosal preparation, however, contains both villus and crypt epithelial cells. Therefore, DHF reductase activity was also determined in a relatively pure villus preparation since the crypt cells probably contain significant amounts of DHF reductase and are not normally involved with absorption. In contrast to the DHF reductase activity in the total mucosal preparation, DHF reductase specific activity was significantly greater in the supernatant fraction of jejunal villi compared to that of ileal villi.

TABLE IV

DHF Reductase Specific Activity in Villus and Total Mucosal Homogenates from Rat Jejunum and Ileum*

\begin{tabular}{lcc}
\hline & Jejunum & Ileum \\
\hline Total mucosa & $235 \pm 40 \ddagger$ & $155 \pm 30$ \\
Villi & $105 \pm 12 \S$ & $36 \pm 3$
\end{tabular}

\footnotetext{
* Mean \pm SEM. DHF reductase activity expressed as nanomoles DHF reduced per milligram protein per hour at $37^{\circ} \mathrm{C}$ was determined on paired tissues from six rats. $\ddagger P<0.2$ compared with ileal total mucosa. $\S P<0.001$ compared with ileal villi.
} 


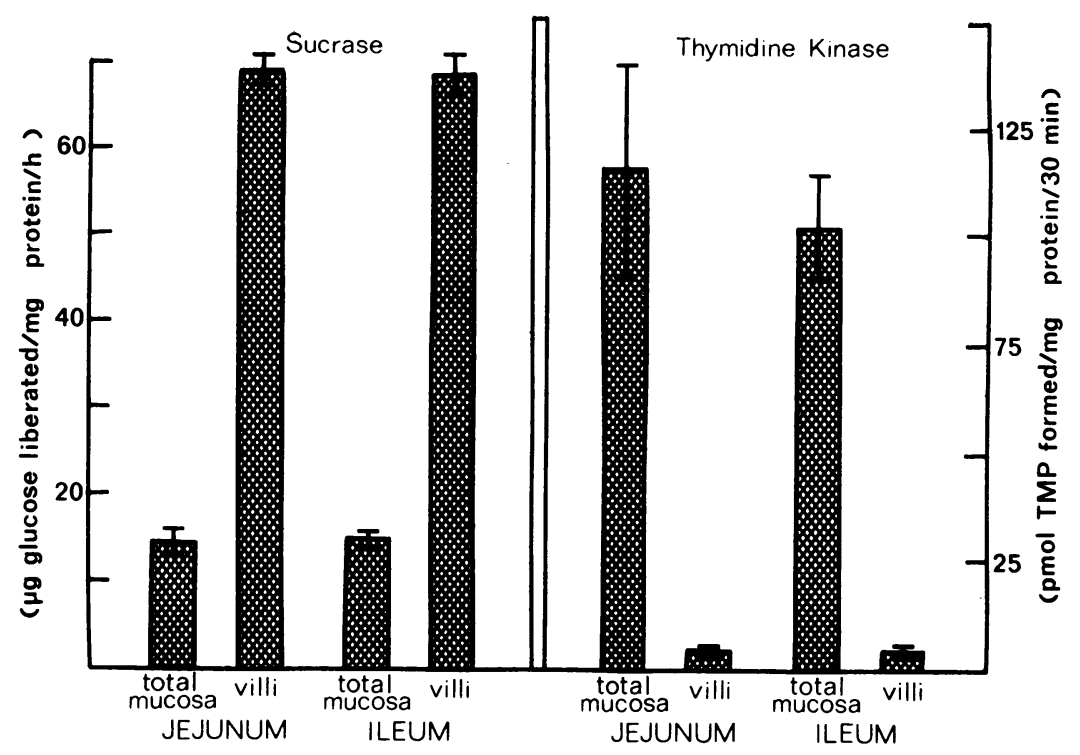

FIGURE 2 Thymidine kinase ( $\mathrm{TK}$ ) and sucrase specific activity in total mucosal and villus preparation from jejunum and ileum. These studies confirm the relative purity of the villus preparation. A fivefold increment in sucrase activity and a 20 -fold decrease in $\mathrm{TK}$ activity were observed in the villus preparation compared with the total mucosal preparation. TMP, thymidine5-monophosphate.

DHF reductase activity in jejunal villi was $105 \pm 12$ $\mathrm{nmol} \mathrm{DHF}$ reduced/h per $\mathrm{mg}$ protein compared with $36 \pm 3$ in ileal villi $(P<0.001)$. The thymidine kinase and sucrase specific activities were measured in the supernatant fractions of jejunal and ileal villus and total mucosal preparation to determine the relative purity of the villus preparation and are demonstrated in Fig. 2. The relative purity of this villus preparation was confirmed by the fivefold augmentation of sucrase specific activity and a 20 -fold diminution of thymidine kinase specific activity when compared with total mucosal homogenates. Further, the ratio of jejunal to ileal activity of sucrase and thymidine kinase was similar in both villus and total mucosal preparation. Further evidence of the presence of villi and absence of crypts in the villus preparation was obtained by light microscopy.

\section{DISCUSSION}

The oral administration of PGA is followed by a rise in the serum folate level, both $\mathrm{PGA}$ and $5-\mathrm{MeFH}_{4}$ (2528). The conversion of PGA to $5-\mathrm{MeFH}_{4}$ occurs in the liver, but some studies have suggested that the small intestine may also participate in the reduction and conversion of $\mathrm{PGA}$ to $5-\mathrm{MeFH}_{4}$ and other folate derivatives.

Both Whitehead and Cooper (29) and Melikian, Paton, Leeming, and Portman-Graham (30) analyzed umbilical vein samples in man after the administration of approximately $10 \mathrm{nmol}$ of PGA and could demonstrate only PGA and no $5-\mathrm{MeFH}_{4}$. Similar results were obtained in dogs by Baugh, Kramdieck, Baker, and Butterworth (31). In contrast, recent studies have demonstrated that reduced folate compounds such as 5 -formyl $\mathrm{FH}_{4}$, are readily converted to the normal plasma folate $\left(5-\mathrm{MeFH}_{4}\right)$ during their absorption across the small intestine (32-34).

Cohen, using a differential microbiological assay, suggested that part of the PGA that crosses the hamster small intestine was converted to $5-\mathrm{MeFH}_{4}(35)$. It is notable that Cohen used an initial mucosal concentration of approximately $25 \mathrm{nM}$. Partial conversion of PGA to $5-\mathrm{MeFH}_{4}$ by rat jejunum has also been reported (36). Snith, Matty, and Blair in studies of everted intestinal sacs from rats employed $10^{-7}$ and $10^{-6} \mathrm{M}$ PGA in their mucosal incubation and reported "a minor radioactive component" with their chromatographic assay system which co-chromatographed with both 5 -formyl $\mathrm{FH}_{4}$ and $5-\mathrm{MeFH}_{4}$ markers (8).

Our studies result in several conclusions. The rat jejunum converts PG.t to 5- $\mathrm{MeFH}_{\text {، }}$. Therefore, PGA may be transferred across the jejunal mucosa in at least two forms: unaltered PGA and PGA converted to $5-\mathrm{MeFH}_{4}$; reduction is not essential to the absorption of PGA. At low mucosal PGA concentrations, however, the conversion of $\mathrm{PGA}$ to $5-\mathrm{MeFH}_{4}$ is qualitatively more important than at higher mucosal PGA concentrations. At higher mucosal PGA concentrations the amount appearing on the serosal side as $5-\mathrm{MeFH}_{4}$ increases, but the percent appearing as $5-\mathrm{MeFH}_{4}$ decreases, an ob- 
servation which suggests that the conversion of $5-\mathrm{MeFH}_{4}$ is a saturable process. These results may explain conflicting observations on the production of $5-\mathrm{MeFH}_{4}$ by the intestinal mucosa during absorption of PGA. What is found in the serosal solution or in the peripheral blood depends upon the PGA concentration in the mucosal incubation media, the surface area and time available for absorption, the quantity of folate in the sample to be analyzed, and the sensitivity of the assay method used to identify the various folate analogues. With higher mucosal concentrations of PGA, 5-MeFH، may not be identified, even though significant absolute quantities of $5-\mathrm{MeFH}_{4}$ may be present. Conversely, $5-\mathrm{MeFH}_{4}$ will be more readily identified when the percent of $\mathrm{PGA}$ converted to $5-\mathrm{MeFH}_{4}$ is greater; a phenomenon observed at low initial mucosal PGA concentrations. Indeed, in those studies which have not demonstrated 5-MeFH، a relatively high initial PGA concentration was employed. Our studies readily demonstrated conversion to $5-\mathrm{MeFH}_{4}$ when 7 or $20 \mathrm{nM}$ PGA was used, but when a high PGA concentration $(2,000 \mathrm{nM})$ was present, minimal conversion was noted.

The conversion of PGA to 5-MeFH4 involves reduction of FH4 by DHF reductase and subsequent methylation to 5-MeFH، (24). MTX, a DHF reductase inhibitor, markedly reduced the appearance of $5-\mathrm{MeFH}_{4}$ in the serosal medium, presumably by inhibiting the first step of the process. Further, there is a correlation between the location of DHF reductase activity in the intestinal mucosa and the appearance of $5-\mathrm{MeFH}_{4}$. DHF reductase specific activity is significantly greater in the jejunum than in the ileum, and the folate appearing on the serosal side as $5-\mathrm{MeFH}_{4}$ is also significantly greater in the jejunum than in the ileum.

DHF reductase activity was determined in the villus as well as in the total mucosal tissue preparation since the crypt region, an area of active DNA and protein synthesis, might contain significant amounts of DHF reductase and so mask differences in the specific activities between jejunal and ileal villi. The use of sucrase and thymidine kinase as enzyme markers to verify the purity of the villus preparation is based on the work of Fortin-Magana, Hurwitz, Herbst, and Kretchmer (37) who demonstrated that greater sucrase activity was present in villi of the rat intestine than in crypt preparations and greater thymidine kinase activity in crypt preparations than in villi. Measurement of these enzyme activities in our preparations also indicated that the villus preparation contained mainly villi, not crypt epithelium (Fig. 2).

An unexpected finding was that the total folate transferred across the jejunum incubated in the presence of MTX and across the ileum was greater than the total folate transferred across the jejunum in the absence of
MTX. One explanation of these results (Table II) is that a significant portion of the newly reduced and methylated folate is retained by the jejunal mucosa following its production. Presumably the ability of the jejunal and ileal mucosa to retain PGA is much less than that of reduced and methylated forms. Further, if the jejunal mucosa is retaining $5-\mathrm{NeFH}_{4}$ or other analogs, then the percent of $5-\mathrm{MeFH}_{4}$ appearing in the serosal media would represent an underestimation of the amount of 5-MeFH4 produced from PGA. This interpretation of the transmural flux data suggesting retention of reduced and methylated folate forms by the jejunum is supported by the tissue accumulation studies. Although mucosal influx of PGA by the jejunum is equal in both the presence and absence of MTX, the presence of MTX significantly inhibits mucosal uptake. Therefore, these results support the hypothesis that PGA enters the mucosal cell, is partly converted to $5-\mathrm{MeFH}_{4}$, and a significant part of the $5-\mathrm{MeFH}_{4}$ remains in the mucosa to account for a relatively low transmural flux of folate. In the presence of MTX, an inhibitor of DHF reductase, PGA influx remains normal, but its conversion to 5- $\mathrm{MeFH}_{4}$ is impaired. Thus, the combination of a decrease in mucosal uptake and an increase in transmural transfer in the presence of MTX suggests that PGA is not retained by the mucosa. It is of interest that MTX causes a $30 \%$ decrease in mucosal uptake and a similar increase $(41 \%)$ in folate transmural movement. Confirmation of this model will require demonstration of $5-\mathrm{MeFH}_{4}$ in tissue extracts, at present beyond the sensitivity of our methods.

Alternate interpretations of the increase in transmural folate movement observed in the presence of MTX should be considered. An increase in mucosal permeability induced by MTX would be compatible with the observed increase in mucosal to serosal transfer. The observation that MTX decreased mucosal uptake of folate and did not alter spontaneous transmembrane potential difference $^{2}$ is evidence against the possibility that alteration of mucosal permeability by MTX is responsible for this observation. An alternate proposal would suggest that in the presence of MTX, the increase in folate absorption is secondary to a counter transport mechanism involving MTX and PGA. In experiments in both L1210 leukemia cells and Ehrlich ascites cells,

\footnotetext{
${ }^{2}$ Transmural electrical potential difference (PD) was monitored during the transmural folate flux determinations. Although PD may reflect several transport parameters, an increase in permeability may be reflected by a decrease in PD. In the MTX experiments the mean ( \pm SEM) PD was $-2.3 \pm 0.2 \mathrm{mV}$ (mucosa negative) and was similar to that observed in jejunal mucosa not exposed to MTX $(-2.0 \pm$ $0.2 \mathrm{mV}$ ). In addition MTX did not significantly increase tissue conductance in these experiments $(20.9 \pm 1.2$ vs. $25.1 \pm$ $2.4 \mathrm{mmho} / \mathrm{cm}^{2}$ ).
} 
Goldman has observed just such a phenomenon involving several folate analogs including $\operatorname{MTX}(38,39)$. Although at present this explanation cannot be completely excluded, there has been little evidence to date to indicate the existence of carrier mediated folate transfer in the intestine. Our previous unexplained observation that 5-formyl $\mathrm{FH}_{4}$ increases 5-MeFH4 transfer, however, is compatible with this counter transport model (17). Additional experiments are required to test this hypothesis.

The results of studies comparing jejunal and ileal transport can also be explained by retention of the newly formed $5-\mathrm{MeFH}_{4}$ by the jejunal mucosa. In the jejunum, both mucosal influx and uptake is greater than ileal mucosal influx and uptake, although transmural folate is greater in the ileum than in the jejunum. This suggests that in the jejunum much of the PGA that enters the mucosa is converted to $5-\mathrm{MeFH}_{4}$ and remains in the mucosa. In the ileum the greater transmural folate flux associated with a smaller mucosal uptake suggests that little of the PGA entering the mucosa is converted to $5-\mathrm{MeFH}_{4}$ and that PGA is not retained.

The extrapolation of these in vitro results to the in vivo state requires caution. The effect of the absence of circulatory, neural, and hormonal influences on intestinal folate absorption and metabolism is not known. Previous in vivo experiments of PGA absorption and the effect of MTX on PGA absorption in the jejunum and ileum of the rat are in agreement with these results. Hepner observed evidence of saturation of PGA disappearance from the lumen of the jejunum but not from that of the ileum (6). Interestingly, intrajejunal MTX impaired PGA absorption, more notably at lower PGA concentrations, than at higher PGA concentrations. Further, MTX did not alter ileal PGA absorption; and subcutaneous MTX did decrease jejunal PGA absorption. Both Hepner's results and our mucosal uptake data suggest that only at low jejunal PGA concentrations does a significant amount of PGA absorption involve a process affected by MTX (6). Although our transmural flux data do not directly agree with the results reported by Hepner (8), it is uncertain how different in vivo and in vitro parameters of absorption correlate.

These studies do not resolve all of the questions regarding the mechanism of PGA transport by the small intestine. They do demonstrate, however, that PGA is converted to $5-\mathrm{MeFH}_{4}$ by the jejunum rather than by the ileum and suggest that this conversion may be a saturable process. Those previous studies which have suggested that PGA absorption may represent a carrier mediated saturable system may have been observing the characteristics of the conversion of PGA to 5-MeFH، by the jejunal mucosa. Further, the newly converted $5-\mathrm{MeFH}_{3}$ is most likely retained and may be utilized by the intestine in addition to transferring the newly formed $5-\mathrm{MeFH}_{4}$ to the portal vein. At low luminal concentrations of PGA comparable to that present in the diet, the intestine may be the primary site of PGA reduction and methylation and production of $5-\mathrm{MeFH}_{4}$.

\section{ACKNOWLEDGMENTS}

The authors acknowledge the expert technical assistance of Claudia Rawlins.

This investigation was supported by U. S. Public Service Grants AM 14,669, AM 05703, CA 08010, and CA 08341.

\section{REFERENCES}

1. Hepner, G. W., C. C. Booth, J. Cowan, A. V. Hoffbrand, and D. L. Mollin. 1968. Absorption of crystalline folic acid in man. Lancet. 2:302.

2. Klipstein, F. A. 1963. The urinary excretion of orally administered tritium-labeled folic acid as a test of folic absorption. Blood. $21: 626$.

3. Burgen, A. S. V., and N. J. Goldberg. 1962. Absorption of folic acid from the small intestine of the rat. Br. J. Pharmacol. Chemother. 19: 313.

4. Turner, J. B., and D. F. Hughes. 1962. The absorption of some B-group vitamins by surviving rat intestine preparations. Q. J. Exp. Physiol. Cogn. Med. Sci. 47: 107.

5. Spencer, R. P., and T. M. Bow. 1964. In vitro transport of radiolabelled vitamins by the small intestine. $J$. Nucl. Med. $5: 251$.

6. Hepner, G. W. 1969. The absorption of pteroylglutamic (folic) acid in rats. Br. J. Haematol. 16: 241.

7. Cox, E. V., M. J. Meynell, IV. T. Cooke, and R. Gaddie. 1958. The folic acid excretion test in the steatorrhea syndrome. Gastroentcrology. 35: 390.

8. Smith, M. E., A. J. Matty, and J. A. Blair. 1970. The transport of pteroylglutamic acid across the small in. testine of the rat. Biochim. Biophys. Acta. 219: 37.

9. Perry, J. 1971. Folate analogues in normal mixed diets. Br. J. Haematol. $21: 435$.

10. Noronha, J. M., and M. Silverman. 1962. Distribution of folic acid derivatives in natural material. I. Chicken liver folates. J. Biol. Chem. 237: 3299.

11. Butterworth, C. E., Jr., R. Santini, Jr., and W. B. Frommeyer, Jr. 1963. The pteroylglutamate components of American diets as determined by chromatographic fractionation. J. Clin. Invest. 42 : 1929.

12. Rosenberg, I. H., and H. A. Godwin. 1971. The digestion and absorption of dietary folate. Gastroenterology. 60: 445 .

13. Nixon, P. F., and J. R. Bertino. 1971. Separation and identification of folate coenzymes on DEAE-Sephadex. Methods Enzymol. 18(Pt. B) : 661.

14. Schultz, S. G., P. F. Curran, R. A. Chez, and R. E. Fruisz. 1967. Alanine and sodium fluxes across mucosal border of rabbit ileum. J. Gen. Physiol. 50: 1241.

15. Schultz, S. G., R. E. Fuisz, and P. F. Curran. 1966. Amino acid and sugar transport in rabbit ileum. J. Gen. Physiol. 49 : 849.

16. Schultz, S. G., and R. Zalusky. 1964. Ion transport in isolated rabbit ileum. I. Short-circuit current and $\mathrm{Na}$ fluxes. J. Gen. Physiol. $47: 567$. 
17. Strum, W., P. F. Nixon, J. R. Bertino, and H. J. Binder. 1971. Intestinal folate absorption. I. 5-methyltetrahydrofolic acid. J. Clin. Invest. 50: 1910.

18. Dietschy, J. M., and M. D. Siperstein. 1965. Cholesterol synthesis by the gastrointestinal tract: localization and mechanisms of control. J. Clin. Invest. 44: 1311.

19. Chello, P. L., and J. J. Jaffe. 1972. Isolation, partial purification and properties of thymidine kinase from Trypanosoma (trypanozoon) Brucei rhodesiense. J. $\mathrm{Pa}$ rasitol. $58: 298$.

20. Furlong, N. B. 1963. A rapid assay for nucleotide kinases using $\mathrm{C}^{14}$ or $\mathrm{H}^{3}$-labeled nucleotides. Anal. Biochem. 5: 515 .

21. Bertino, J. R., J. P. Perkins, and D. J. Johns. 1965. Purification and properties of dihydrofolate reductase from Ehrlich ascites carcinoma cells. Biochemistry. 4: 839.

22. Dahlquist, A. 1968. Assay of intestinal disaccharidases. Anal. Biochem. 22 : 99.

23. Snedecor, G. W., and W. G. Cochran. 1967. Statistical Methods. Iowa State University Press, Ames. 6th edition.

24. Nixon, P. F., and J. R. Bertino. 1970. Interrelationships of Vitamin $\mathrm{B}_{12}$ and folate in man. Am. J. Med. 48: 555.

25. Baker, H., O. Frank, S. Feingold, H. Ziffer, R. A. Gellene, C. M. Leevy, and H. Sobotka. 1965. The fate of orally and parenterally administered folates. $\mathrm{Am}$. J. Clin. Nutr. $17: 88$.

26. Butterworth, C. E., Jr., H. Nadel, E. Perez-Santiago, R. Santini, Jr., and F. H. Gardner. 1957. Folic acid absorption, excretion and leukocyte concentration in tropical sprue. J. Lab. Clin. Med. 50: 673.

27. Chanarin, I., B. B. Anderson, and D. L. Mollin. 1958. The absorption of folic acid. Br. J. Haematol. 4: 156.

28. Spray, G. H., and L. J. Witts. 1952. The utilization of folic acid given by mouth. Clin. Sci. 11: 273.

29. Whitehead, V. M., and B. A. Cooper. 1967. Absorption of unaltered folic acid from the gastro-intestinal tract in man. Br. J. Hematol. 13: 679.

30. Melikian, V., A. Paton, R. J. Leeming, and H. PortmanGraham. 1971. Site of reduction and methylation of folic acid in man. Lancet. $2: 955$.

31. Baugh, C. M., C. L. Kramdieck, H. J. Baker, and C. E. Butterworth, Jr. 1971. Studies on the absorption and metabolism of folic acid. I. Folate absorption in the dog after exposure of isolated segments to synthetic pteroylpolyglutamates of various chain lengths. J. Clin. Invest. 50: 2009.

32. Whitehead, V. M., R. Pratt, A. Viallet, and B. A. Cooper. 1972. Intestinal conversion of folinic acid to 5methyltetrahydrofolate in man. Br. J. Haematol. 22:63.

33. Nixon, P. F., and J. R. Bertino. 1972. Effective absorption and utilization of oral formyltetrahydrofolate in man. N. Engl. J. Med. 286: 175.

34. Chanarin, I., and J. Perry. 1969. Evidence for reduction and methylation of folate in the intestine during normal absorption. Lancet. 1: 776.

35. Cohen, N. 1965. Differential microbiological assay in study of folic acid absorption in vitro by everted intestinal sacs. Clin. Res. 13: 252. (Abstr.)

36. Strum, W. B., P. F. Nixon, J. R. Bertino, and H. J. Binder. 1970. Intestinal absorption of 5-methyltetrahydrofolate (MTHF). Clin. Res. 18: 389. (Abstr.)

37. Fortin-Magana, R., R. Hurwitz, J. J. Herbst, and N. Kretchmer. 1970. Intestinal enzymes: indicators of proliferation and differentiation in the jejunum. Science (Wash. D. C.). $167: 1627$.

38. Goldman, I. D., N. S. Lichtenstein, and V. T. Oliverio. 1968. Carrier-mediated transport of the folic acid analogue, methotrexate, in the L1210 leukemia cell. J. Biol. Chem. 243: 5007

39. Goldman, I. D. 1971. A model system for the study of heteroexchange diffusion: methotrexate-folate interactions in L1210 leukemia and Ehrlich ascites tumor cells. Biochim. Biophys. Acta. 233: 624 